\title{
Surface morphology of soybean, pea, whey protein isolates, and their dried gels
}

\section{Maksym Polumbryk ${ }^{1}$, Olena Shestel ${ }^{2}$, Olha Yatsenko', Nataliia Yuschenko', Ulyana Kuzmyk ${ }^{1}$}

\author{
1 - National University of Food Technologies, Kyiv, Ukraine \\ 2 - Cherkassy State Technological University, Cherkassy, Ukraine
}

\section{Keywords:}

Morphology

Proteins

Whey

Soybean

Pea

\section{Article history:}

Received 12.08.2018

Received in revised form

26.11.2018

Accepted 28.03.2019

Corresponding author:

Maksym Polumbryk

E-mail:

polumbr@nuft.edu.ua

DOI: $10.24263 / 2304-$

974X-2019-8-1-8

\section{Abstract}

Introduction. The hydrocolloids of plant and animal origin are widely used in food technologies, especially in the meat and dairy products manufacturing. The aim of this study was to investigate the surface morphology of some proteins isolates of plant origin and hydrated gels made from them.

Materials and methods. The protein isolates of soybean, pea and whey as well as $\kappa$-carrageenan, and guar gum were used in this study. We prepared gels of the isolates with low fats milk at the ratio $1: 6$ and 1:8. Structural changes of soybean, pea, and whey protein as well as their hydrates were observed by use of scanning electron microscope JSM-6700F.

Results and discussion. The presence of coarse particles was observed in the samples of soybean and pea isolates, whereas sample of whey isolates had spherical shaped particles only. We found that, pea and soybean isolates did not differ significantly in their sample size, which was approximately $40 \mu \mathrm{m}$. The low hydration level of the isolates at a ratio of 1:5 lead to smooth surface formation with the large number of holes. The remains of the large globules can be identified in the sample of hydrated pea isolate as the edges of dried spheres, which sizes are similar to those of initial isolates. Increased hydration level up to $1: 8$ resulted in the crosslinking between the proteins macromolecules and lead to carcass formation. Polysaccharides incorporation into the mixture of stabilizers resulted in the surface formation of gels which morphological features were similar to those of protein isolates of pea, soybean, and whey. However, this was further resulted in the gel structure formation with the minor crosslinking

Conclusions. Increased amount of milk in the gels resulted in the development of 3D structure formation, as expected. Pea isolate was characterized by the great ability to the crosslinking between macromolecules of proteins. 


\section{Introduction}

Several dairy products, such as yogurt, curd, and butter are widely present in a human diet. Modern trends in the substitution of raw materials of animal origin lead to thorough examination of structural features of the plant materials. Several beans, primarily soybean and pea are widely used as a source of protein since their chemical composition and technological properties are similar to the animal proteins [1,2]. Moreover, consumption of these proteins is beneficial for human health due to a high amount of essential amino acids [1].

Introduction of these proteins into the formulations of dairy products has resulted in the reduction of fats content without any adverse effects in the texture of the final products [3]. Usually protein isolates are used in a preliminary hydrated form, so that it is necessary to evaluate effective water: protein ratio in each certain case. It should be noted, that insufficient amount of water may have negative effect on the technological properties, causing increased viscosity, unpleasant aftertaste, and low yield of final product [4]. It should be noted, that too much water resulted in the complicated retention of food carcass. Mixture or composition of several protein isolates are used in order to obtain food products, particularly meat and dairy with desired properties. This approach was an effective in the sausages production made from meat emulsion and in the curd manufacturing too [5]. Unfortunately, it is necessary to find effective ratio of hydrocolloids in the each certain case. Thus, structural changes of protein isolates during hydration are the subject of careful study, which may reveal the mechanisms of hydrocolloids transformations, and will help to simplify the search of their ratio in compositions.

Scanning electron microscopy is an important technique which has been widely used in the careful screening of the surface of food materials [6-8]. This method has found to be useful in the investigations of surface morphology of fermented sausages at different level of starch, fats and egg white in the formulation [9], and analysis of texture of frankfurter sausages with the modified fats profile [10]. The authors have suggested that sensory properties of the final products depend on the structural features of the product surface [10]. The more uniformly distributed holes on the surface the better quality of the final product. Application of SEM in the analysis of dairy products gives an opportunity to quantify differences of the surface parameters at the different duration of technological process [11]. Also, this method was useful in the analysis of fats distribution in the dairy products, such as butter, curd, milk, and other. It should be noted, that usually frozen samples of dairy product have examined by cryo scanning electron microscopy [12]. This technique is an extremely useful in the investigations of distribution of casein particles, fats, and oils as well as their form, shape, and transformations during technological treatment or storage [12]. Nevertheless, SEM method has used in the quantitative examination of the texture of dairy products too [8].

Purpose. The purpose of this study is a surface examination of several hydrated gels of protein isolates at different milk: protein ratio.

\section{Materials and methods}

\section{Materials and samples preparation}

The protein isolates of soybean, pea and whey as well as $\kappa$-carrageenan, and guar gum were purchased from Roeper (Germany). All the isolates were of high purity ( $\geq 95 \%$. ) grade. 
Low fats milk $(0.05 \%$. ) was purchased from a local supermarket "Auchan". We prepared gels of the isolates with low fats milk at the ratio 1:6 and 1:8. We have previously reported that the lower isolate: milk ratio was resulted in extremely high viscosity of the gel so that there were no possibilities of utilization of these gels for the food manufacturing purposes [3]. Moreover, we prepared the gel sample of the pea isolate, which was swelled during 24 $\mathrm{h}$. The samples were retrained during 22-24 h. prior to heat treatment in order to achieve a maximal hydration of the samples. Further, the gels of protein isolates hydrated by skimmed milk at the ratio $1: 6$ and 1:8 were exposed to thermal treatment at $82 \pm 2{ }^{\circ} \mathrm{C}$ during 5 and 10 minutes, respectively. This was done order to accelerate development of the protein network. Petri 's dish was layered by protein hydrates and dried at room temperature for $24 \mathrm{~h}$ followed by rinsing in chloroform for $40 \mathrm{~min}$ in order to remove particles of fats from the samples surfaces, and, finally, the samples were sustained in ethanol due to necessity of water elimination from the surfaces.

We have previously reported that the application of hydrocolloids composition based on the isolate of whey proteins resulted in the increased stabilization of butter paste [13]. The samples of gel of composition with low fats milk at the ratio $1: 6$ and 1:8 were prepared. The following components have used in the composition: isolate of milk proteins, isolate of whey proteins, guar gum, and $\kappa$-carrageenan at the ratio 10: 3: 0.3: 0.05 .

\section{Scanning electron microscopy set-up}

Structural changes of soybean, pea, and whey protein as well as their hydrates were observed by use of scanning electron microscope JSM-6700F (JEOL, Japan. The microstructure of protein isolates was observed at ambient temperature. Samples were covered with platinum layer with the width of $10 \mathrm{~nm}$ prior to the experiments. The microphotographs were obtained at the accelerating voltage which was $10 \mathrm{kV}$ and probe current $0,65 \mathrm{nA}$. Dried samples of the protein hydrates $(0.2 \times 0.2 \mathrm{sm}$, and $0.5-1 \mathrm{~mm}$ in depth) were fixed with the steel holder followed by operating under vacuum at the temperature 20 $\pm 0.1{ }^{\circ} \mathrm{C}$.

\section{Results and discussion}

In the first stage, we tried to assess morphological parameters of initial isolates. The presence of coarse particles was observed in the samples of soybean (figure 1b) and pea isolates (figure $1 \mathrm{c}$ ), whereas sample of whey isolates had spherical shaped particles only (figure 1a). We found that, pea and soybean isolates didn't differ significantly in their sample size. The particles with the mean diameter of $18-21 \mu \mathrm{m}$ preferably were presented in these isolates and minor amount of fraction with the average size $40 \mu \mathrm{m}$ was detected in these samples. In contrast, the sample of whey isolated consisted mainly large globules with the average size of about $40 \mu \mathrm{m}$ with inclusion other particles, which cannot be separated into the certain fractions. It should be noted that, prolonged shooting of the samples resulted in the wrinkled globules formation which was observed due to the low thermal resistance of these samples.

Previously $\kappa$-carrageenan and guar gum were used as a minor components of mixture of stabilizers [13]. The structural features of $\kappa$-carrageenan are different to those of protein isolates. We didn't detect presence of globules on the surface in the sample of this hydrocolloid (figure 1d). The presence of coarse particles and ellipsoid-like particles with the diameters $110-120 \mu \mathrm{m}$ and $60-70 \mu \mathrm{m}$ was observed on the surface of the sample of $\kappa$ carrageenan 

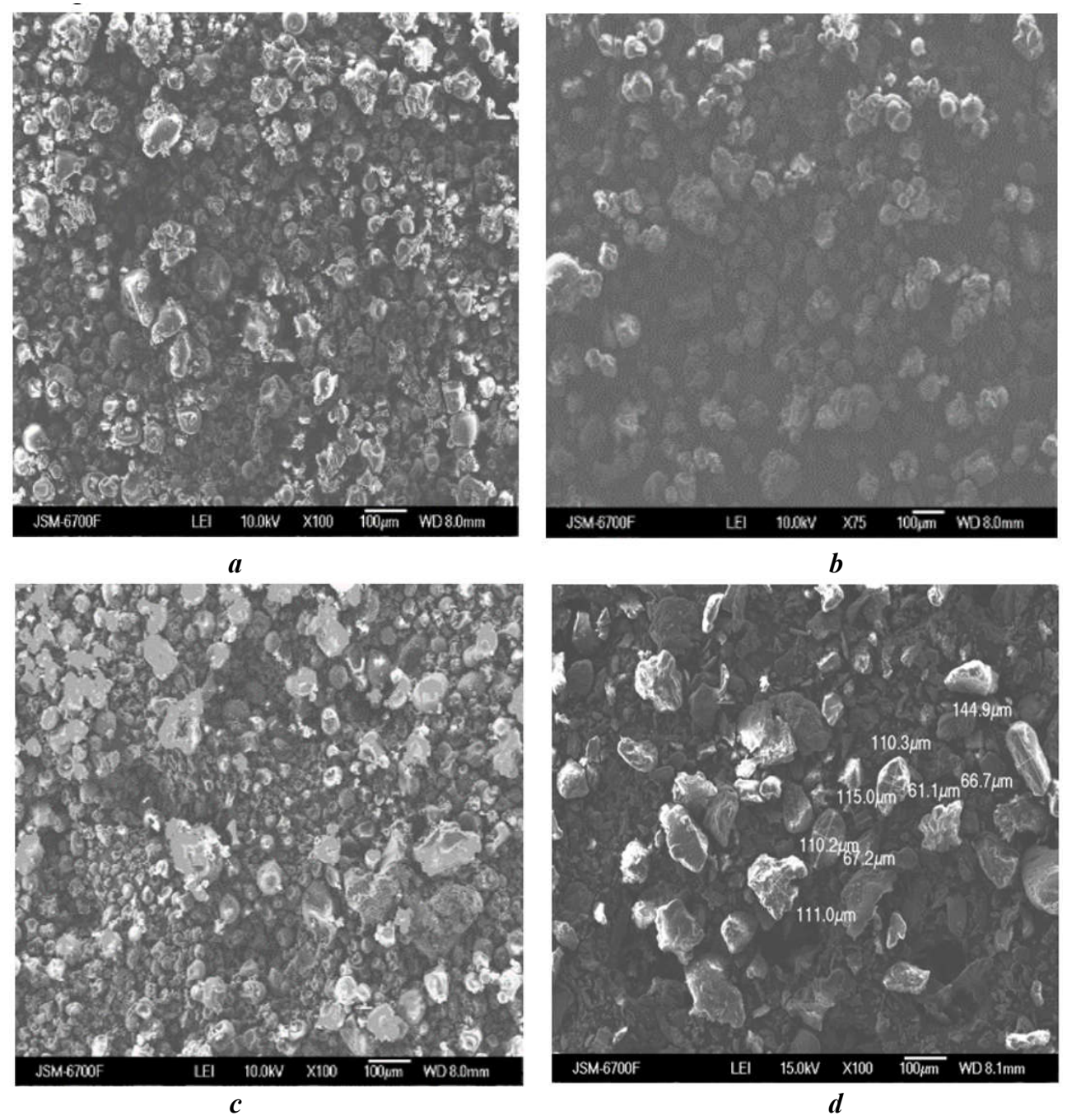

Figure 1. Electron microphotographs of whey protein isolate (a), soybean isolate (b), pea isolate (c), and k-carrageenan (d)

The low hydration level of the isolates at a ratio of 1:5 lead to smooth surface formation with the large number of holes (figure 2). These holes were filled with water before drying. In our opinion, insufficient hydration of proteins resulted in the quternary structure disruption, while interconnections between protein macromolecules didn`t observed. Insight into figure 2D revealed that remains of the large globules can be identified in the sample of hydrated pea isolate as the edges of dried spheres, which sizes are similar to those of initial isolates. In our opinion the presence of fracturings on the surface of pea gels was most likely associated with incoplete hydration of the sample.Also, small globules, which were less than $1 \mu \mathrm{m}$ were, still presented on the surface of other isolates. The presence of $\kappa$-carrageenan on the surface of dried gels wasn`t observed. 


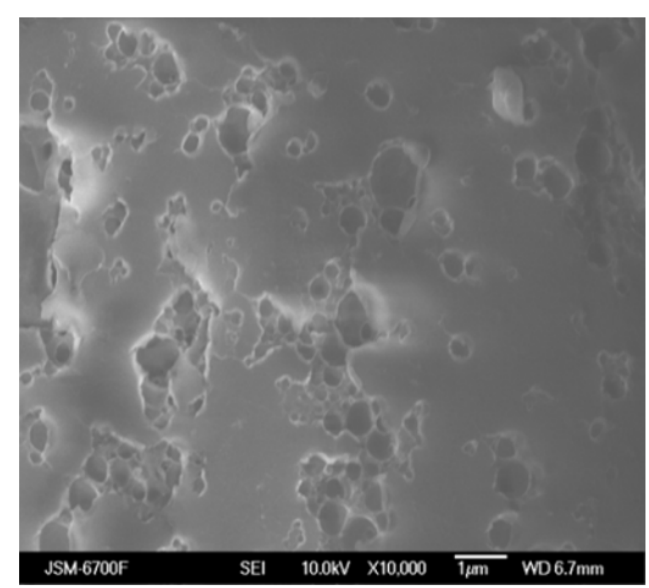

$\boldsymbol{a}$

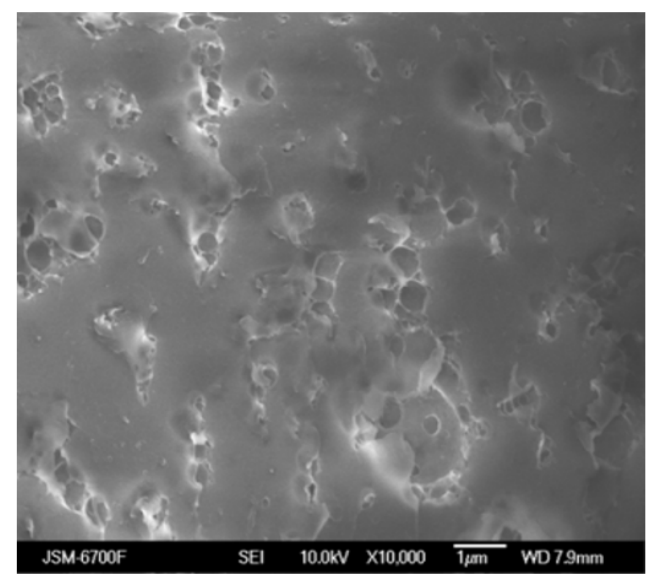

c
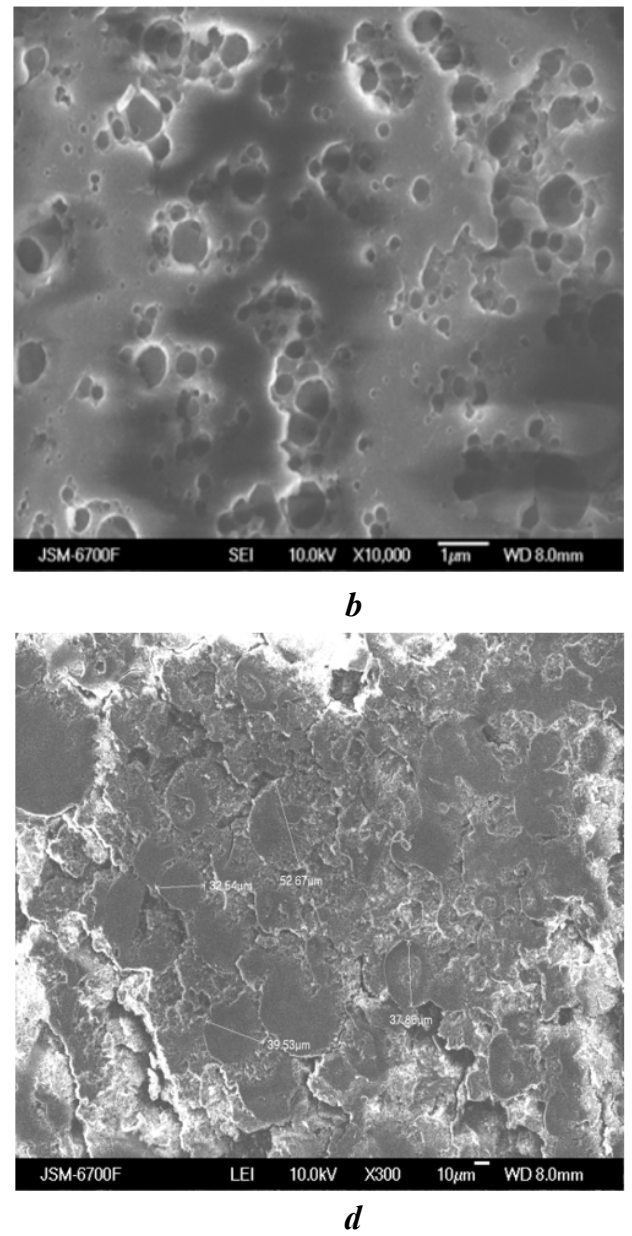

Figure 2. SEM images of dried gels of samples of whey protein isolate (a), spybean isolate (b), preliminary swelled pea isolate (c), and pea isolate without swelling (d) at protein: milk ratio 1:5

Further hydration of protein isolates was resulted in the surface formation without any globules. Rise of milk amount in the isolate: milk ratio up to 1:6 increases hydration of proteins. As it can be seen from the figure 3 all the samples of dried gels are characterized by smooth texture with large number of small holes. In contrast to the previous set of dried gels, preliminary hydration of isolates at the 1:6 isolate: milk ratio has negligible effect on the surface morphology of the gels.

We observed decreased number of pores and their diameter in the sample with 1:8 hydration ratio in compare to sample with 1:8 hydration ratio. By other words, increased hydration was resulted in the less porous structure formation. Similar findings were observed by Rovira et al. in the dried samples of goat chees [8]. A greater number of pores was found in the sample which was preliminary swelled during $24 \mathrm{~h}$. This sample was characterized by the higher development of the proteins crosslinking than sample without preliminary swelling. 


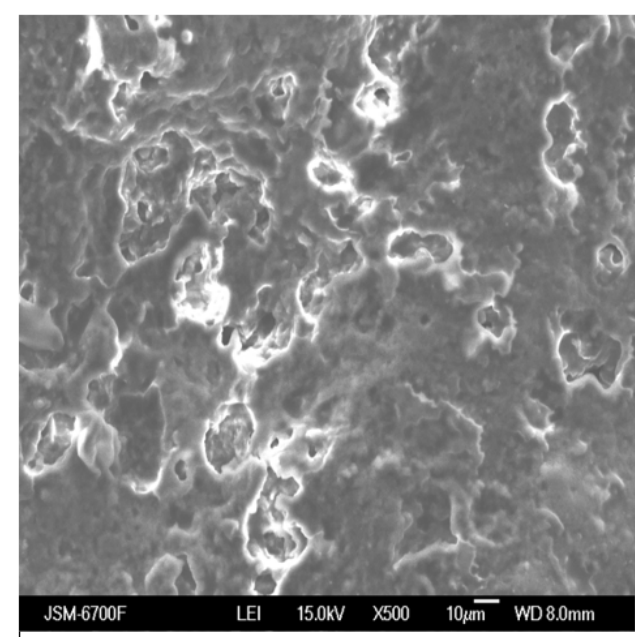

$\boldsymbol{a}$

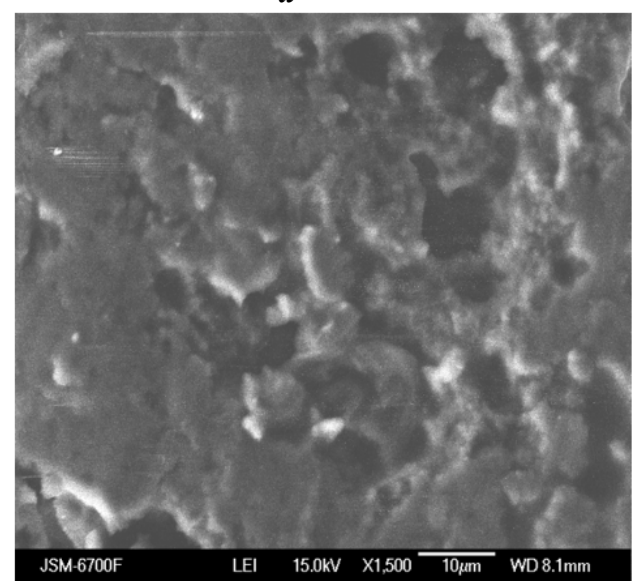

$c$

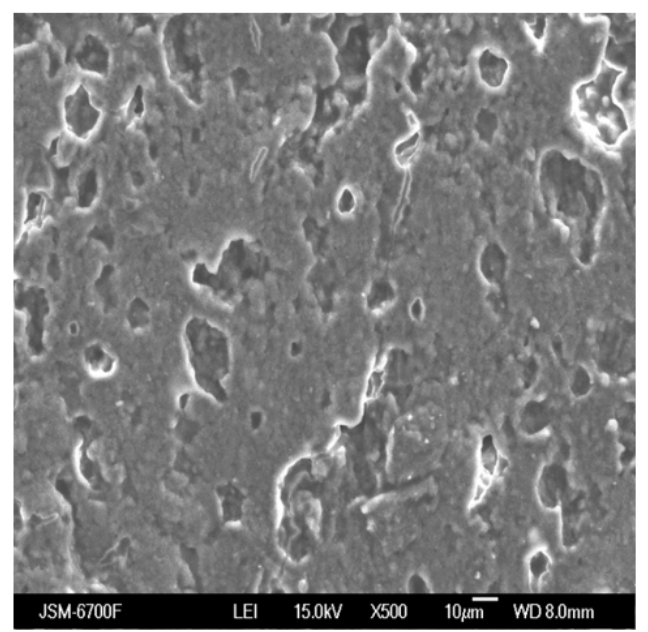

$\boldsymbol{b}$

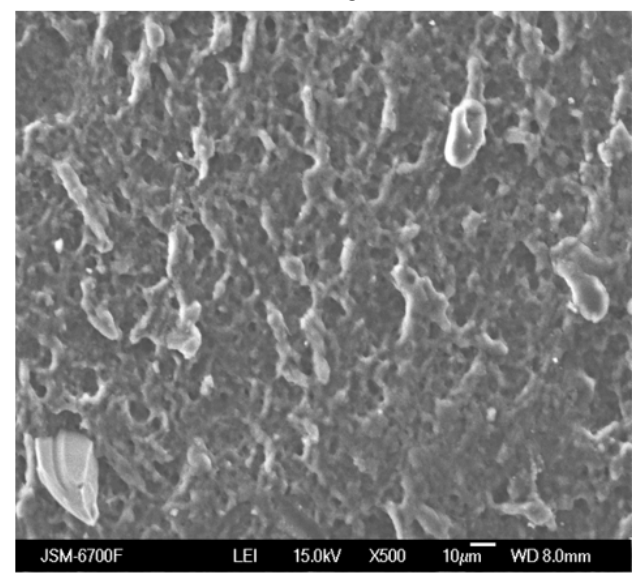

$\boldsymbol{d}$

Figure 3. Electron microphotographs of dried gels of whey protein isolate (a), spybean isolate (b), preliminary swelled pea isolate (c), and pea isolate without swelling (d) at protein: milk ratio 1:6

Further hydration of these isolates at the ratio 1:8 was resulted in the crosslinking between different residues of protein macromolecules and three-dimenional net structure formation (fig. 4). This was particularly true in the sample of pea isolate (fig.4c), which surface consisted numerous holes and free spaces. Liu and coauth. found that the development of free dimensional structure of soybean proteins in their gels strongly dependent on the processing type [14]. Microwave heating was resulted in more viscoelsatic structure of soybean gels than the gels obtained by conventional method [14]. 


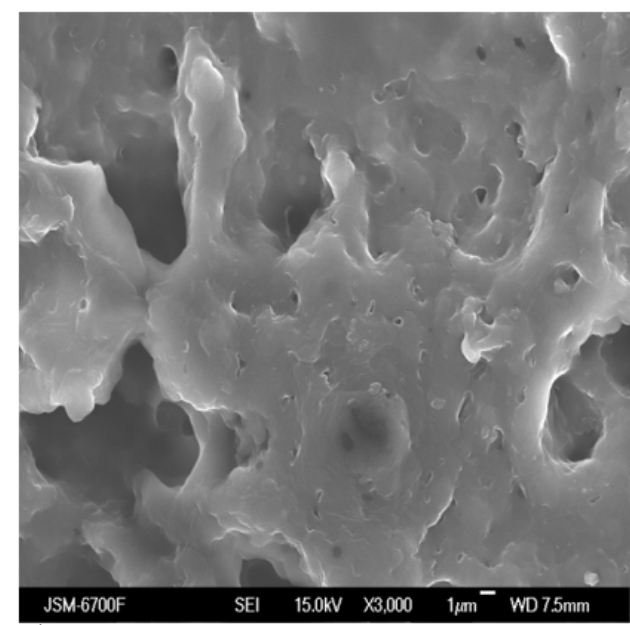

$\boldsymbol{a}$

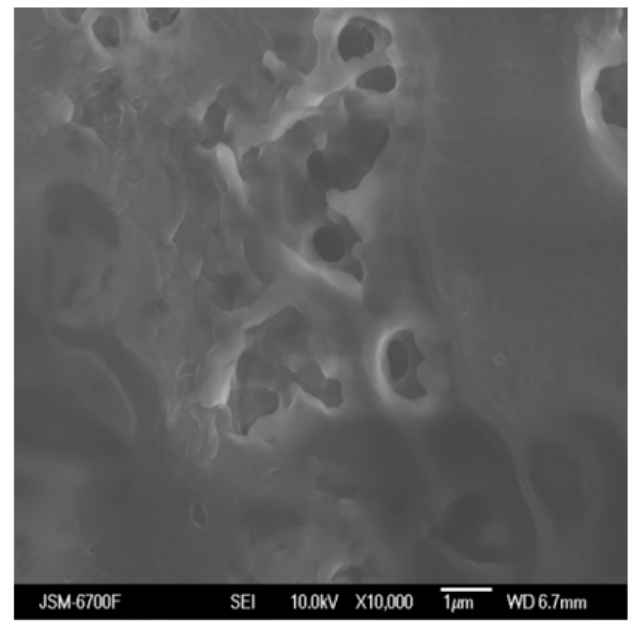

c

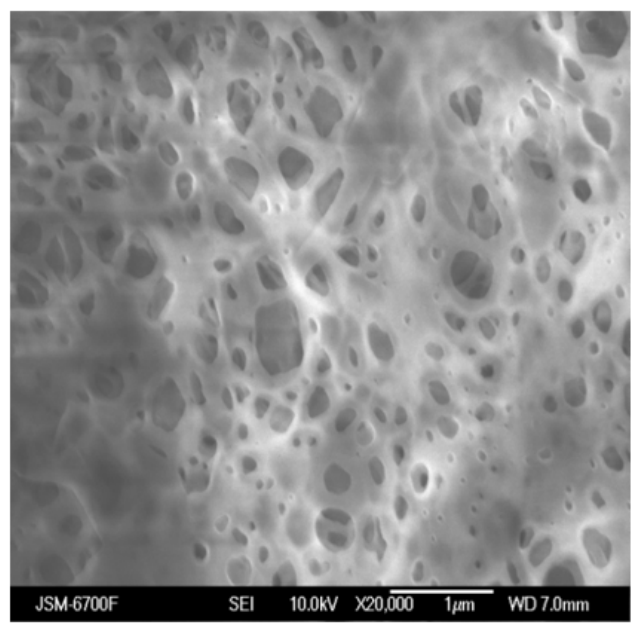

$b$

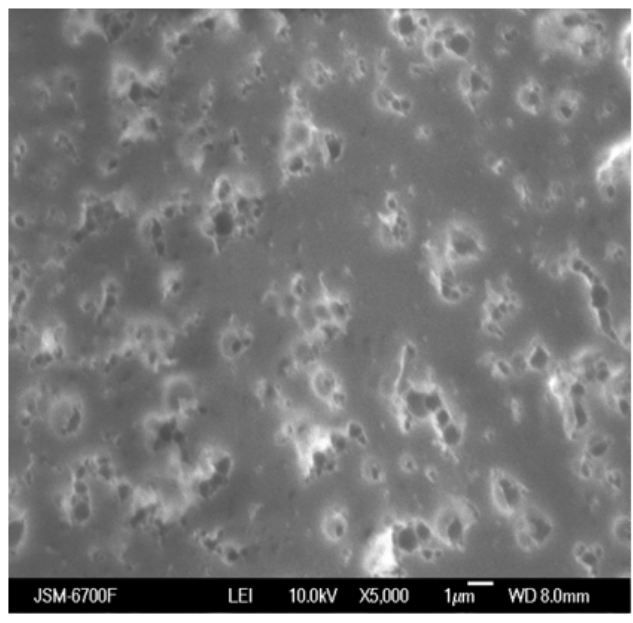

$d$

Figure 4. SEM images of hydrated samples of whey protein isolate (a), soybean isolate (b), and pea isolate (c), and pea isolate without swelling (d) at protein: milk ratio 1:8

We didn't studied with higher isolate: milk ratio due to both full hydration of proteins and adverse effect on the texture of the gels caused by high amount of water.

\section{Discussion}

Utilization of protein isolates in the formulations of cheese and curd has lead to decrease of total cost of final products and has a positive efeect on the overall quality of the final product. Usually these isolates have used in the preliminary hydrated form, which resulted in the necessity of evaluation of the most effective water: isolate ratio. In this study scanning electron microsocopy was used for this purpose. Also, we used milk as water substitute in the gels formation. It has several advantages, especially presence of proteins which structural features are similar to proteins isolates. We prepared three series of gels of protein isolates 
with a isolate:milk ratio 1:5, 1:6, and 1:8. The samples were dried at ambient temperature for $24 \mathrm{~h}$ and treated with chloroform and ethylalcohol in order to eleminate water and fats from the samples surfaces.

We observed fractures on the surface of gel made from not swelled pea isloate and globules remains on the surfaces of the other samples of gels prepared from isolate protein and milk in the ratio of 1:5. In our opinion these findings suggest that the milk amount isn't enough for the full hydration of proteins. Probably, the more prolonged drying will cause similar findings in the other samples with low hydration level. It should be noted, that "air side" surface was rough whereas the surface which was contacted with the flat glass was smooth. Similar observations were indicated by Kowalczyk et al. during observation of pea gels [15]. Whey have suggested that rougness of the surface which has contacted with air related to the presence of small $(5-20 \mu \mathrm{m})$ particles of pea isolates [15]. From figure 2, it can be seen that the presence of globules of the isolates didn't detected on the surface of the samples. All the images of dehydrated protin fels given in figure 2 obtained from smooth side.

Increased hydration level up to 1:8 resulted in the crosslinking between the proteins macromolecules and carcass formation (figure 4). The samples didn't differ by their structural features. It is known that the development of microstructure starts from rearrangement of casein micelles of whey proteins. As it has observed by Rovira et al., increased production time of goat cheese resulted in the continous network of proteins formation due to binding of weakly hydrated aggregates of the proteins [8]. Also, formation of protein carcass has observed by Lin et al, in the samples of tofu made from soybean milk [16]. SEM images of dehydrated tofu samples has characterized by large number of the small pores between protein macromolecules, which cuased three dimensional honeycomb-like structure formation [16].

The gels produced from milk and protein isolates are extremely important in the production of batter pastes. Several polysaccharides usually added into the composition in order to improve their technological properties. Utilization of $\kappa$-carrageenan in these products make it possible to decrease amount of composition of stabilizers, while guar gum incorporation may resulted in the improvement of final product during freezing and thawing processes. We have found that the incorporation of $\kappa$-carrageenan has resulted in the formation of highly crosslinked gels which cannot be used in the batter pastes. We prepared samples of gels made from low fat milk and composition of hydrocolloids based on milk proteins and whey isolate proteins at the composition and milk ratio 1:6 and 1:8. As it can be seen from figure 5a, incorporation of polysaccharides into the mixture of stabilizers resulted in the surface formation of gels which morphological features were similar to those of protein isolates of pea, soybean, and whey (figure 3). However, the sample of gel, which was hydrated by low fat milk, had the structure with the minor crosslinking (figure 5). In our opinion, crosslinking between molecules of proteins is a key factor of gels structure in determining of possibility of the gel application in the butter pastes. The strong crosslinking, which was observed in the sample of pea isolate, was pointed that it would not to be used in these products manufacturing without significant changes of technological processes and amount of ingredients in the formulations, while the isolates of soybean and whey are the better choice for this purpose. Therefore utilization of the composition of the stabilizers allows decreasing the development of crosslinking between and decrease amount of added hydrocolloids. 


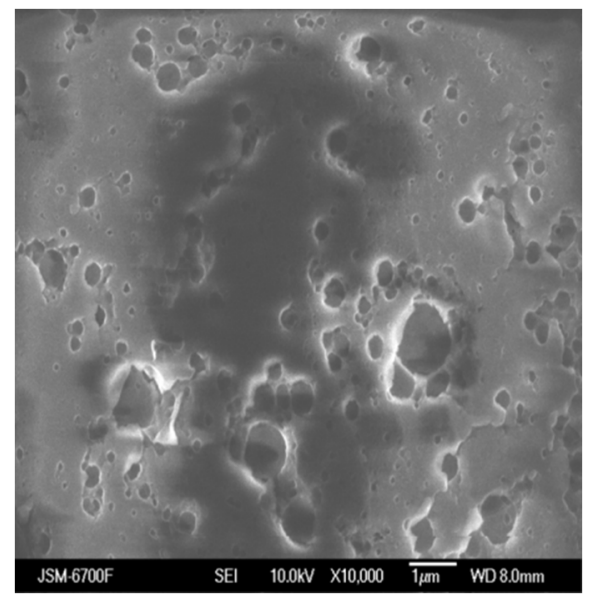

$a$

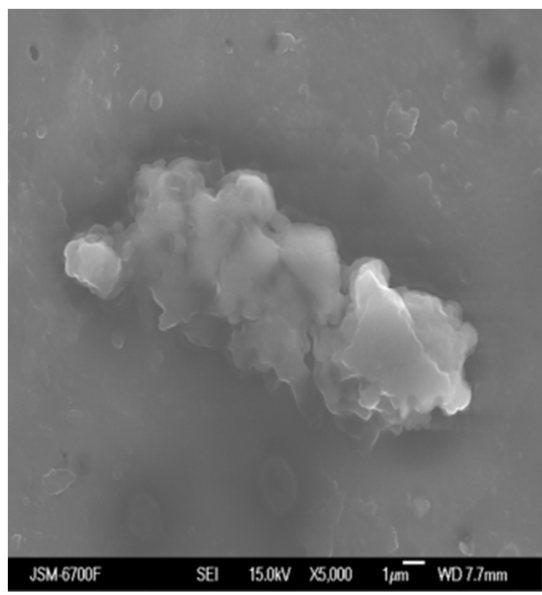

$\boldsymbol{b}$

Figure 5. SEM images of hydrated samples of hydrocolloid composition at protein: milk ratio 1:6 (a) and 1:8 (b)

\section{Conclusions}

This study proved that SEM is a promising technique which helps to choose components in the composition of stabilizer dependently on the product type. It was found that the increased amount of milk resulted in the development of 3D structure formation, as expected. Pea isolate was characterized by the great ability to the crosslinking between macromolecules of proteins. Therefore it cannot be used in the butter pastes, but may be especially useful in the cheese manufacturing. This study is limited by a low number of studied proteins isolates. Further study on larger number of proteins isolates is necessary to investigate role of hydration level on the 3D- structure development.

\section{References}

1. Han B.-Z.; Rombouts F. M.; Nout M.R. (2004), Amino acid profiles of sufu, a Chinese fermented soybean food, J. Food Compos. Anal., 37, pp. 689-698.

2. Xiong T., Ye X., Su Y., Chen X., Sun H. et al. (2018), Identification and quantification of proteins at adsorption layer of emulsion stabilized by pea protein isolates, Coll. Surf. B Biointerfaces., 171, pp. 1-9, DOI: 10.1016/j.colsurfb.2018.05.068.

3. Guo Y., Zhang X., Hao W., Xie Y., Chen L. et. al. (2018), Nano-bacterial cellulose/soy protein isolate complex gel as fat substitutes in ice cream model, Carbohydr Polym., 198, pp. 620-630, Doi: 10.1016/j.carbpol.2018.06.078.

4. Kochubei-Lytvynenko O., Yatsenko O., Yushchenko N., Kuzmyk U. (2018), Investigation of functional-technological properties of soya protein, EUREKA: Life Sciences., №. 5, pp. 39-43, Doi: 10.21303/2504-5695.2018.00716.

5. Kochubei-Lytvynenko O., Yatsenko O., Yushchenko N., Kuzmyk U. (2018), A stabilizing system for butter pastes based on the dry concentrates of milk protein. 
East.-Europ. J. Enterprise Technol., 5(11), pp. 30-36, DOI: 10.15587/17294061.2018.143105.

6. Niu H., Xia X., Wang C., Kong B., Liu Q. (2018), Thermal stability and gel quality of myofibrillar protein as affected by soy protein isolates subjected to an acidic $\mathrm{pH}$ and mild heating, Food Chem., 242, pp. 188-195, DOI: 10.1016/j.foodchem.2017.09.055.

7. Chen J. (2007), Surface texture of foods: perception and characterization, Crit. Rev. Food Sci. Nutr. 47, pp. 583-98. doi: 10.1080/10408390600919031.

8. Rovira S., Lopez M.B., Ferrandini E., Laencina J. (2011), Microstructure quantification by scanning electron microscopy and image analysis of goat cheese curd, J. Dairy Sci. 94 , pp.1091-1097, DOI: 10.3168/jds.2010-3996.

9. Mohamed H.M., Emara M.M., Nouman T.M. (2011), Effect of cooking temperatures on characteristics and microstructure of camel meat emulsion sausages, J. Sci. Food Agric., 96, p. 2990-2997. doi: 10.1002/jsfa.7468.

10. Caballo J., Fernandez P., Barreto, G.,et.al. (1996), Morphology and texture bologna sausage as related to content of fat, starch and egg white, J. Food Sci, 61(3), pp. 652-655, DOI: https://doi.org/10.1111/j.1365-2621.1996.tb13179.x

11. Liu, W., Lanier, T. (2015), Combined use of variable pressure scanning electron microscopy and confocal laser scanning microscopy best reveal microstructure of comminuted meat gels, LWT - Food Sci. Technol., 62, pp. 1027-1033., DOI: 10.1016/j.lwt.2015.02.001.

12. Ong L., Dagastine R R., Kentish S.E., Gras S.L. (2011), Microstructure of milk gel and cheese curd observed using cryo scanning electron microscopy and confocal microscopy, LWT - Food Sci. Technol., 44, pp. 1291-1302, DOI: 10.1016/j.lwt.2010.12.026.

13. Kochubei-Lytvynenko O., V.M. Pasichnyi, Yatsenko O., Yushchenko N., Kuzmyk U. (2018), Prospects of usage of pea protein isolate in buttery pastes technology, Sci. Lett. NUFT., 24(6), pp. 152-159, DOI: 10.24263/2225-2924-2018-24-6-19.

14. Liu H.H., Kuo M.I. (2011) Effect of microwave heating on the viscoelastic property and microstructure of soy protein isolate gel, J. Texture Stud., 42, p. 1-9.

15. Kowalczyk D., Gustaw W., Zieba E., Lisiecki S. et. al. (2016), Microstructure and functional properties of sorbitol-plasticized pea protein isolate emulsion films: Effect of lipid type and concentration, Food Hydrocoll., 60(4), pp. 353-363, DOI: 10.1016/j.foodhyd.2016.04.006.

16. Lin H.F., Lu C.P., Hsieh J.F., Kuo M.I. (2016), Effect of ultrasonic treatment on the rheological property and microstructure of tofu made from different soybean cultivars, Innovative Food Sci. Emerging Technol., 37, pp. 98-105, DOI: 10.1016/j.ifset.2016.08.013. 